\title{
Potencial antimicrobiano e antiaderente do óleo essencial de Lavandula híbrida grosso contra cepas de Klebsiella pneumoniae
}

Antimicrobial and non-stick potential of essential oil of Lavandula hybrida grosso against colony of Klebsiella pneumoniae

Potencial antimicrobiano y no adictivo del aceite esencial de Lavandula híbrido grueso de Klebsiella pneumoniae Elaine Roberta Leite de SOUZA

José Henrique de Araújo CRUZ ${ }^{1}$ José Lucas Soares FERREIRA ${ }^{1}$

Heloisa Mara Batista Fernandes de OLIVEIRA² Abrahão Alves de OLIVEIRA FILHO ${ }^{3}$

\begin{abstract}
${ }^{1}$ Cirurgiã(o) Dentista. Centro de Saúde e Tecnologia Rural, Universidade Federal de Campina Grande, UFCG 58708-110 Patos - PB, Brasil ${ }^{2}$ Farmacêutica em Hospital Universitário Ana Bezerra, Universidade Federal do Rio Grande do Norte, UFRN, 59078-970, Natal - RN, Brasil ${ }^{3}$ Professor(a) Doutor(a) do Curso de Graduação em Odontologia. Centro de Saúde e Tecnologia Rural, Universidade Federal de Campina Grande, UFCG 58708-110 Patos/PB, Brasil
\end{abstract}

\section{Resumo}

Introdução: A utilização de produtos de origem vegetal na odontologia constitui uma alternativa na prevenção e combate de diversas patologias que acomentem os seres humanos. A Klebsiella pneumoniae é uma bactéria gram-negativa que está intimamente relacionada com a pneumonia nosocomial e que possui a capacidade de intaivar um grande numero de agentes antimicrobianos. A Lavandula Híbrida é uma espécie derivada da união da Lavandula angustifólia Miller com a Lavandula latifólia Linn. Essa espécie apresenta as variedades Abrialli, Grosso, Provence, Impress purple, e Super, sendo a variedade Grosso como a que mais demonstrou atividade antimicrobiana. Objetivo: Avaliar a atividade antibacteriana e antiaderente do óleo essencial de Lavandula Híbrida Grosso contra cepas de K. pneumoniae. Metodologia: Os ensaios foram realizados utilizando as técnicas de microdiluição em caldo em placas de 96 poços para determinação da CIM e CBM e técnica de tubos inclinados para determinação da CIMA ao vidro, na presença de 5\% de sacarose. Resultados: obteve-se que o óleo essencial de Lavandula híbrida Grosso possui uma moderada atividade antibacteriana contra as cepas de K. pneumoniae visto pela $\mathrm{CIM}_{50}=1.024 \mu \mathrm{g} / \mathrm{ml}$, possuindo também um potencial bacteriostático. Quanto a sua atividade antiaderente, observou-se que a concentração do óleo capaz de inibir a adesão do microrganismo a parede do tudo foi de 1:32 enquanto que para o digluconato de clorexidina $0,12 \%$ foi de 1:8. Conclusão: a Lavandula Híbrida demonstra ser eficaz como agente antimicrobiano e antiaderente para o controle e prevenção da infecção por Klebseilla pneumonia.

Descritores: Plantas Medicinais; Ação Antimicrobiana; Aderência Bacteriana.

\section{Abstract}

Introduction: The use of products of plant origin in dentistry is an alternative in the prevention and combat of several pathologies that accompany humans. Klebsiella pneumoniae is a gram-negative bacterium that is closely related to nosocomial pneumonia because it has the ability to inactivate a large number of antimicrobial agents. Lavandula Híbrida, also known as Lavandin is a species derived from the union of Lavandula angustifolia Miller with Lavandula latifolia Linn. This species presents the varieties Abrialli, Grosso, Provence, Impress purple, and Super. Among them, the species that most demonstrated antimicrobial potential was the Grosso variety. Objective: to evaluate the antibacterial and nonstick activity of Lavandula Hybrid Grosso essential oil against strains of Klebsiella pneumoniae. Method: The assays were carried out using broth microdilution techniques in 96-well plates for determination of Minimum Inhibitory Concentration (MIC) and Minimum Bactericidal Concentration (MBC) and sloped tube technique for the determination of Minimum Inhibitory Adherance Concentration (MICA) to the glass, in the presence of 5\% sucrose. Results: It was obtained that the essential oil of Lavandula hybrida Grosso has a moderate antibacterial activity against the strains of $K$. pneumoniae seen by the $\mathrm{MIC}_{50}$ equal to $1024 \mu \mathrm{g} / \mathrm{ml}$, also possessing a bacteristatic potential. As to its antiadherent activity, it was observed that the concentration of oil capable of inhibiting the adhesion of the microorganism to the wall of the whole was $1: 32$ whereas for the chlorhexidine digluconate $0,12 \%$ was $1: 8$. Conclusion: In accordance with the results of the present study, Lavandula Hybrid demonstrated to be effective as an antimicrobial and anti-adherent agent for the control and prevention of Klebseilla pneumoniae infection.

Descriptors: Medicinal Plants; Antimicrobial Action; Bacterial Adhesion.

\section{Resumen}

Introducción: El uso de productos de origen vegetal en odontología constituye una alternativa en la prevención y combate de diversas patologías que afectan a los humanos. Klebsiella pneumoniae es una bacteria gramnegativa que está estrechamente relacionada con la neumonía nosocomial y tiene la capacidad de activar una gran cantidad de agentes antimicrobianos. Lavandula Hybrid es una especie derivada de la unión de Lavandula angustifolia Miller con Lavandula latifolia Linn. Esta especie tiene las variedades Abrialli, Grosso, Provence, Impress purple y Super, siendo la variedad Grosso la que más actividad antimicrobiana mostró. Objetivo: Evaluar la actividad antibacteriana y antiadherente del aceite esencial de Lavandula Hibrida Grosso contra cepas de K. pneumoniae. Metodología: Las pruebas se llevaron a cabo utilizando técnicas de microdilución de caldo en placas de 96 pocillos para determinar el MIC y CBM y la técnica de tubo inclinado para determinar el CIMA en el vidrio, en presencia de sacarosa al 5\%. Resultados: se obtuvo que el aceite esencial de Lavandula híbrido Grosso tiene una actividad antibacteriana moderada contra las cepas de K. pneumoniae observadas por MIC50 = 1,024 $\mu \mathrm{g} / \mathrm{ml}$, que también tiene un potencial bacteriostático. En cuanto a su actividad antiadherente, se observó que la concentración de aceite capaz de inhibir la adhesión del microorganismo a la pared del tubo fue 1:32, mientras que para el digluconato de clorhexidina $0.12 \%$ fue 1: 8. Conclusión: Lavandula Hybrid demuestra ser eficaz como agente antimicrobiano y antiadherente para el control y prevención de la infección por neumonía de Klebseilla.

Descriptores: Plantas Medicinales; Acción Antimicrobiana; Adhesión Bacteriana.

INTRODUÇÃo

A cavidade bucal é hospedeira de diversos microrganismos, abrigando cerca de metade de toda a microflora existente no corpo humano o que inclui várias espécies de fungos, vírus e bactérias ${ }^{1,2}$. A descamação fisiológica das superfícies corporais dificulta o acúmulo desordenado de microrganismos no corpo, porém, devido à presença de superfícies não 
descamativas na cavidade bucal, tal controle é possível apenas com a higienização oral regular ${ }^{3}$.

O biofilme dental, chamado também de placa bacteriana compreende o principal fator relacionado com o surgimento de cárie dentária e doenças periodontais ${ }^{4}$. Sua formação se dá por intermédio de um processo ordenado e dinâmico que vão desde a formação da película adquirida, adesão microbiana inicial e maturação da placa bacteriana ${ }^{5}$. Como métodos para o controle do biofilme pode-se citar a escovação mecânica e uso de colutórios, como o digluconato de clorexidina a $0,12 \%$, entretanto, os efeitos colaterais advindos da utilização prolongada da clorexidina estimulam a busca por outros métodos químicos de controle do biofilme ${ }^{6,7}$.

Oliveira et al. $^{8}$ relatam que patógenos envolvidos em infecções respiratórias não são comumente encontrados na microbiota bucal de indivíduos saudáveis, contudo pacientes hospitalizados estão predispostos à colonização do biofilme oral por esses microrganismos. Além disso, os componentes do biofilme podem prevenir a penetração de agentes antibióticos no biofilme, tornando esses patógenos mais resistentes aos antimicrobianos, dificultando sua eliminação ${ }^{3,8}$.

A pneumonia nosocomial representa uma infecção no parênquima pulmonar nas vias aéreas inferiores, sendo diagnosticadas 48 horas após a internação do paciente, não estando presentes nem incubadas anteriormente à data de internação ${ }^{9}$. Entre os microrganismo associados ao desenvolvimento dessa infecção pode-se citar: Acinetobacter, Staphylococcus aureus, Esherihia coli, Klebsiella pneumoniae, Pseudomonas aeruginosa, Enterobacter e Proteus mirabiis sendo que tais organismos foram achados tanto na microbiota oral quanto pulmonar em vários estudos, reforçando a correlação entre o biofilme bucal com o desenvolvimento de infecções respiratórias ${ }^{9,10}$.

A Klebsiella pneumoniae é uma bactéria gram-negativa, pertencente à família das Enterobacteriaceae, encapsulada, que cresce frequentemente em meio aeróbio, com forma de bastão, não esporulado e não móvel, cujo tamanho pode variar de 0,3 a $1 \mu$ de diâmetro e 0,6 a $6 \mu$ de comprimento e que está intimamente relacionada com a pneumonia nosocomial. Por produzir a enzima Klebsiella pneumoniae carbapenemase (KPC), que possui a capacidade de inativar um grande número de agentes antimicrobianos, é atualmente dita como a principal causadora de certas infecções devido à resistência que confere aos medicamentos ${ }^{11,12}$.

Saigg e Silva ${ }^{13}$ fundamentam que a utilização de plantas medicinais, que são ricas em substâncias biologicamente ativas, é capaz de estimular reações metabólicas que contribuem para a prevenção e tratamento de diversas doenças. Os óleos essenciais, assim como seus componentes majoritários (terpenos, flavonóides, taninos, etc), possuem diversas propriedades farmacológicas documentadas tornando-os também importantes fontes de novos fármacos ${ }^{14}$. Assim, 0 potencial antimicrobiano dos óleos essenciais e seus componentes tem despertado interesse por serem compostos, em sua maioria, com baixa toxicidade, boa eficácia e baixo custo ${ }^{15}$.

A Lavandula híbrida, também conhecida como Lavandin é uma espécie derivada da união da Lavandula angustifólia Miller com a Lavandula latifólia Linn. Essa espécie apresenta as variedades Abrialli, Grosso, Provence, Impress purple, e Super. Entre eles, a espécie que mais demostrou potencial antimicrobiano foi a variedade Grosso. Apesar de não ser bem visto pela indústria de perfumes pelo seu elevado conteúdo de 1-8 cineol e de cânfora, o óleo essencial de Lavandula híbrida desperta interesse da indústria farmacêutica por apresentar-se como um bom agente antimicrobiano visto em estudos contra bactérias gram+ e gram-. Entretanto, a falta de estudos sobre suas atividades e seu mecanismo de ação, principalmente contra outros patógenos instiga a necessidade de se realizar mais pesquisas ${ }^{16}$.

Sendo assim, o objetivo do presente trabalho é avaliar a atividade antibacteriana e antiaderente do óleo essencial de Lavandula híbrida Grosso contra cepas de Klebsiella pneumoniae usando para isso a análise da sua Concentração Inibitória Mínima (CIM), Concentração Bactericida Mínima (CBM) e Concentração Inibitória Mínima de Aderência (CIMA).

\section{MATERIAL E MÉTODO}

\section{Ensaios in vitro}

- Substancia teste

O óleo essencial de Lavandula Híbrida Grosso foi adquirido da Indústria Via Aroma® (Porto Alegre - RS). Para a realização dos ensaios farmacológicos, a substância foi solubilizada em DMSO e diluído em água destilada. A concentração de DMSO (dimetilsulfóxido) utilizada foi inferior a 0,1\% v/v. - Espécies bacterianas e meio de cultura Foram utilizadas as seguintes bactérias 
de origem clínica: Klebsiella pneumoniae (ATCC 13883, Kp 101, Kp 102, Kp 103, Kp 104 e Kp 105). Todas as cepas foram mantidas em meio Ágar Muller Hinton (AMH) a uma temperatura de $4{ }^{\circ} \mathrm{C}$, sendo utilizados para os ensaios repiques de 24 horas em $\mathrm{AMH}$ incubados a $35^{\circ} \mathrm{C}$. No estudo da atividade antimicrobiana foi utilizado um inóculo bacteriano de aproximadamente 1,5 x $108 \mathrm{UFC} / \mathrm{ml}$ padronizado de acordo com a turbidez do tubo 0,5 da escala de McFarland ${ }^{17,18}$.

\section{- Determinação da Concentração Inibitória Mínima (CIM)}

A concentração inibitória mínima do óleo essencial foi determinada pela técnica de microdiluição em caldo ${ }^{17,18}$. Foram utilizadas placas de 96 orifícios estéreis e com tampa. Em cada orifício da placa, foi adicionado $100 \mu \mathrm{L}$ do meio líquido caldo Muller Hinton duplamente concentrado. Em seguida, $100 \mu \mathrm{L}$ da emulsão do óleo na concentração inicial de $2048 \mu \mathrm{g} / \mathrm{ml}$ (também duplamente concentrado), foram dispensados nas cavidades da primeira linha da placa. E por meio de uma diluição seriada em razão de dois, foram obtidas as concentrações de 1024, 512, 256, 128, 64, 32, 16, 8 e $4 \mu \mathrm{g} / \mathrm{ml}$, de modo que na primeira linha da placa encontra-se a maior concentração e na última, a menor concentração. Por fim, foi adicionado 10 $\mu \mathrm{L}$ do inóculo de aproximadamente 1,5 x 108 $\mathrm{UFC} / \mathrm{ml}$ das espécies bacterianas nas cavidades, onde cada coluna da placa refere-se a uma cepa de bactéria, especificamente.

Paralelamente, realizou-se o controle positivo com o antibacteriano cloranfenicol. Um controle de microorganismo foi realizado colocando-se nas cavidades $100 \mu \mathrm{L}$ do mesmo caldo Mueller Hinton duplamente concentrado, $100 \mu \mathrm{L}$ de água destilada estéril e $10 \mu \mathrm{L}$ do inóculo de cada espécie. Para verificar a ausência de interferência nos resultados pelos solventes utilizados na preparação da emulsão, no caso o DMSO, foi feito um controle no qual foram colocados nas cavidades $100 \mu \mathrm{L}$ do caldo duplamente concentrado, $100 \mu \mathrm{L}$ de DMSO e $10 \mu \mathrm{L}$ da suspensão bacteriana. Um controle de esterilidade do meio também foi realizado, onde colocou-se $200 \mu \mathrm{L}$ do caldo Mueller Hinton em um orifício sem a suspensão das bactérias.

As placas foram assepticamente fechadas e incubadas a $35^{\circ} \mathrm{C}$ por 24 horas para ser realizada a leitura. A CIM para óleo foi definida como a menor concentração capaz de inibir visualmente 0 crescimento bacteriano verificado nos orifícios quando comparado com o crescimento controle. Os experimentos foram realizados em duplicata.

\section{- Determinação da Concentração Bactericida Mínima (CBM)}

A concentração bactericida mínima (CBM) do óleo também foi determinada para as cepas de bactérias. Após a leitura da CIM em 24 horas, alíquotas de $20 \mu \mathrm{L}$ foram retiradas de cada poço da placa de microtitulação que não apresentaram crescimento bacteriano, e transferidas para poços de uma nova placa de microtitulação contendo $100 \mu \mathrm{L}$ de caldo Muller Hinton, desprovidas de qualquer antimicrobiano. As placas inoculadas foram assepticamente fechadas e incubadas a $35{ }^{\circ} \mathrm{C}$, e as CBMs foram registradas após $48 \mathrm{~h}$. A CBM foi definida como a menor concentração do óleo essencial que resultou em inibição visível do crescimento do micro-organismo ${ }^{19,20}$.

- Determinação da Concentração Inibitória Mínima de Aderência (CIMA)

A Concentração Inibitória Mínima de Aderência (CIMA) do óleo foi determinada na presença de sacarose a $5 \%$, de acordo com $^{21}$ usando-se concentrações correspondentes do óleo essencial puro até a diluição 1:1024. A partir do crescimento bacteriano, a cepa de Klebsiella pneumoniae 102 foi cultivada a $37^{\circ} \mathrm{C}$ em caldo Mueller Hinton (DIFCO, Michigan, Estados Unidos), depois foram distribuídos 0,9 $\mathrm{ml}$ do subcultivo em tubos de ensaio e, em seguida, adicionado $0,1 \mathrm{ml}$ da solução correspondente às diluições do óleo essencial. A incubação foi feita a $37^{\circ} \mathrm{C}$ por 24 horas com tubos inclinados a $30^{\circ}$. A leitura foi realizada através da observação visual da aderência da bactéria às paredes do tubo, após a agitação do mesmo. $\mathrm{O}$ ensaio foi realizado em duplicata. $\mathrm{O}$ mesmo procedimento foi realizado para o controle positivo, o digluconato de clorexidina a $0,12 \% \quad$ (Periogard®), Colgate-Palmolive Company, Nova York, EUA). Foi considerada a CIMA a menor concentração do agente em contato com sacarose que impediu a aderência ao tubo de vidro.

RESULTADOS E DISCUSSÃO

Nas Tabelas 1 e 2 estão representados, respectivamente, a Concentração Inibitória Mínima (CIM) e a Concentração Bactericida Mínima (CBM) do óleo essencial de Lavandula híbrida grosso contra as cepas de Klebsiella pneumoniae. Com relação a esses resultados, observa-se que o valor de $\mathrm{CIM}_{50}$ foi de 1.024 $\mu \mathrm{g} / \mathrm{ml}$ e que não foi possível encontrar o valor de CBM pois os testes demonstraram valores acima de $1.024 \mu \mathrm{g} / \mathrm{ml}$. Os resultados encontrados acerca da atividade antiaderente do óleo essencial de Lavandula Híbrida Grosso contra as cepas Klebsiella pneumoniae encontram-se descritos na Tabela 3, assim 
como sua comparação com o digluconato de clorexidina $0,12 \%$. Foi observado que o óleo essencial de Lavandula hibrida Grosso apresentou uma CIMA de 1:32, enquanto 0 digluconato de clorexidina $0,12 \%$ foi de $1: 8$, ou seja, uma concentração 4 vezes menor que o principal antimicrobiano utilizado para tratamento de diversas afecções que acometem a cavidade oral.

Tabela 1. Concentração inibitória mínima (CIM) em $\mu \mathrm{g} / \mathrm{ml}$ do do Óleo essencial de Lavandula Híbrida Grosso contra diferentes cepas de Klebsiella pneumoniae

\begin{tabular}{c|c|c|c|c|c|c}
\hline \multicolumn{7}{c}{ Lavandula Híbrida Grosso } \\
\hline & $\begin{array}{c}K p \text { ATCC } \\
13883\end{array}$ & $\begin{array}{c}K p \\
101\end{array}$ & $\begin{array}{c}K p \\
102\end{array}$ & $\begin{array}{c}K p \\
103\end{array}$ & $\begin{array}{c}K p \\
104\end{array}$ & $K p 105$ \\
\hline $1.024 \mu \mathrm{g} / \mathrm{ml}$ & - & + & + & + & + & - \\
\hline $512 \mu \mathrm{g} / \mathrm{ml}$ & - & - & + & - & + & - \\
\hline $256 \mu \mathrm{g} / \mathrm{ml}$ & - & - & - & - & - & - \\
\hline $128 \mu \mathrm{g} / \mathrm{ml}$ & - & - & - & - & - & - \\
\hline $64 \mu \mathrm{g} / \mathrm{ml}$ & - & - & - & - & - & - \\
\hline $\begin{array}{c}\text { Controle } \\
\text { negativo }\end{array}$ & - & - & - & - & - & - \\
\hline $\begin{array}{c}\text { Controle } \\
\text { positivo }\end{array}$ & + & + & + & + & + & + \\
\hline $\begin{array}{l}\text { Dados da Pesquisa } \\
\text { Legenda: (+) Inibição (-) Sem inibição }\end{array}$
\end{tabular}

Tabela 2. Concentração Bactericida Mínima (CBM) em $\mu \mathrm{g} / \mathrm{ml}$ do Óleo essencial de Lavandula Híbrida Grosso contra diferentes cepas de Klebsiella pneumoniae

\begin{tabular}{|c|c|c|c|c|c|c|}
\hline \multicolumn{7}{|c|}{ Lavandula Híbrida Grosso } \\
\hline & $\begin{array}{c}\text { Kp ATCC } \\
13883\end{array}$ & $\begin{array}{l}K p \\
101\end{array}$ & $\begin{array}{c}K p \\
102\end{array}$ & $\begin{array}{c}K p \\
103\end{array}$ & $\begin{array}{c}K p \\
104\end{array}$ & $\begin{array}{c}K p \\
105\end{array}$ \\
\hline $\begin{array}{l}1.024 \\
\mu \mathrm{g} / \mathrm{ml}\end{array}$ & - & - & - & - & - & - \\
\hline $\begin{array}{l}512 \\
\mu \mathrm{g} / \mathrm{ml}\end{array}$ & - & - & - & - & - & - \\
\hline
\end{tabular}

Tabela 3. Concentração Inibitória Mínima de Aderência em $\mu \mathrm{g} / \mathrm{ml}$ do do Óleo essencial de Lavandula Híbrida Grosso e do digluconato de Clorexidina $0,12 \%$ contra diferentes cepas de Klebsiella pneumoniae 102.

\begin{tabular}{l|c|c|c|c|c|c|c|c}
\hline \multicolumn{1}{c}{ Lavandula Híbrida Grosso } \\
\hline $\begin{array}{l}\text { Concentração } \\
\mathrm{em} \mu \mathrm{g} / \mathrm{ml}\end{array}$ & $1: 1$ & $1: 2$ & $1: 4$ & $1: 8$ & $1: 16$ & $1: 32$ & $1: 64$ & $1: 128$ \\
\hline \multicolumn{8}{c}{ Digluconato de clorexidina o,12 } \\
\hline $\begin{array}{l}\text { Concentração } \\
\text { em } \mu \mathrm{g} / \mathrm{ml}\end{array}$ & $\mathbf{1 : 1}$ & $\mathbf{1 : 2}$ & $\mathbf{1 : 4}$ & $\mathbf{1 : 8}$ & $\mathbf{1 : 1 6}$ & $\mathbf{1 : 3 2}$ & $\mathbf{1 : 6 4}$ & $\mathbf{1 : 1 2 8}$ \\
\hline & - & - & - & - & + & + & + & + \\
\hline
\end{tabular}

Dados da Pesquisa

Legenda: ( +) Inibição ( - ) Sem inibição

As plantas que apresentam potencial terapêutico utilizadas no cuidado da saúde tradicional compreendem uma importante fonte de novos compostos biologicamente ativos. Tal fato fortalece a capacidade de desenvolver novos medicamentos a partir de plantas medicinais e seus derivados que tragam a mesma eficácia, segurança e biocompatibilidade $^{22}$ assim como motivam os estudos com plantas e seus derivados, visando seu emprego como fonte de recursos terapêuticos e como um imenso provedor de biomoléculas ${ }^{23}$.
As plantas podem sintetizar cerca de 200.000 metabólitos secundários podendo ser denominados também de fitoquímicos ${ }^{24}$. Dentre eles, os óleos essenciais, conhecidos também como óleos voláteis, óleos etéreos ou essência estão presentes nas plantas como produto natural, derivados do metabolismo secundário das plantas e que contêm compostos aromáticos voláteis, estando envolvidos no seu mecanismo de defesa ${ }^{25}$.

Os óleos essenciais podem ter um papel importante como antimicrobianos, e embora a composição química e a atividade antioxidante do gênero Lavandula tenha sido investigada ${ }^{26,27}$, há menos dados disponíveis sobre sua atividade antimicrobiana, particularmente sobre aplicação sobre patógenos ${ }^{16}$.

De acordo com Sartoratto et al. ${ }^{28}$ para uma atividade antimicrobiana ser classificada como forte para óleos essenciais, estes devem possuir a CIM de até $500 \mu \mathrm{g} / \mathrm{ml}$, moderada para CIM de 600 a $1500 \mu \mathrm{g} / \mathrm{ml}$ e fraca para CIM acima de $1500 \mu \mathrm{g} / \mathrm{ml}$. Assim, os resultados encontrados no presente estudo demonstram que a atividade antimicrobiana do óleo essencial de Lavandula Híbrida Grosso possui uma moderada inibição frente as cepas de Klebsiella pneumoniae testadas observáveis pela $\mathrm{CIM}_{50}$ de $1024 \mu \mathrm{g} / \mathrm{ml}$.

Para um composto ser considerado bactericida ou bacteriostático de acordo com seu CBM, segundo Hafidh et al. $^{29}$, esta deve ser, respectivamente, igual ou duas vezes maior que o CIM ou o CBM deve ser maior que duas vezes $O$ CIM. Os resultados obtidos demonstram que o óleo essencial de Lavandula Híbrida Grosso apresenta um potencial bacteriostático frente as cepas de Klebsiella pneumoniae..

O estudo realizado por Bajalan et al. ${ }^{30}$ buscando analisar a composição química e a atividade antibacteriana de Lavandas híbridas cultivadas na região nordeste do Iran alguns microrganismos, entre eles a $K$. pneumoniae utilizando 0 método de disco-difusão. Os resultados demonstraram que os óleos essenciais testados apresentaram uma moderada atividade bacteriana contra $K$. pneumoniaie e E. coli. Tais resultados entram em conformidade com os apresentados nesse estudo, onde também foi obtido uma atividade inibitória moderada da $L$. híbrida contra a $K$. pneumoniae.

Gandolfo et al. ${ }^{6}$, Munis et al. $^{7}$ e de Andrade et al. ${ }^{31}$ relatam que o método mais aceito para o controle do biofilme bucal compreende a sua remoção mecânica através da escovação dentária, entretanto, vários 
autores relatam que a utilização de agentes químicos que atuem como coadjuvantes para o controle do biofilme, como o digluconato de clorexidina $0,12 \%$ (forma mais utilizada na odontologia já que apresenta maior solubilidade à substância), são bons métodos complementares de assepsia.

A clorexidina consiste no agente antimicrobiano de origem sintética mais potente e estudado, apresentando uma ótima eficácia e utilizado como padrão ouro pata testar a potência de outros agentes antimicrobianos ${ }^{32}$. Dentre as propriedades apresentadas por essa substância, pode-se citar a substantividade; eficácia como agente antimicrobiano; segurança, e um amplo espectro de ação, sendo capaz de atuar tanto em microrganismos gram- quanto gram $+{ }^{33}$. Entretanto, os diversos efeitos colaterais causados pelo uso prolongado do Digluconato de Clorexidina $0,12 \%$ como a precipitação de cálculo dentário, a perda do paladar e o manchamento dentário estimulam a buscar por outros agentes antimicrobianos ${ }^{34}$.

Castro $^{35}$ acrescenta também que na presença de inconvenientes para realização de uma adequada higienização da cavidade oral, como a falta de motivação dos indivíduos ou em situações que o indivíduo apresente limitações locomotoras, como no caso de pacientes internados em UTIs, e tendo como objetivo primário controlar o biofilme dental é oportuno e essencial a associação de métodos químicos (colutórios) aos métodos mecânicos (escovação) para o controle da microbiota oral.

Em relação a sua atividade antiaderente, observou-se que o óleo essencial usado no presente estudo demonstrou uma melhor propriedade do que o digluconato de clorexidina $0,12 \%$, visto pela menor concentração capaz de inibir a aderência de biofilme ao tubo, sendo 1:32 para o óleo essencial de Lavandula híbrida Grosso e 1:8 para o digluconato de clorexidina $0,12 \%$.

Um estudo realizado por Rajasekharan et al. ${ }^{36}$ buscou analisar o potencial antiaderente do extrato de Arctium lappa (raiz de bardana) e de um de seus componentes, o ácido clorogênico contra em isolados clínicos de Klebsiella pneumoniae. Como resultados, podese concluir que tanto o extrato quando o acido obteve uma significativa atividade antiaderente contra as cepas de $K$. pneumoniae, demonstrando assim que o extrato de raiz de bardana e seu composto podem seu usados como metodo alternativo para o controle da presença de $K$. pneumoniae no biofilme. Tais resultados reforçam o pressuposto de que óleos essenciais podem ser utilizados como método alternativo para o controle do biofilme.

CONCLUSÃO

Diante dos resultados obtidos, observase um elevado potencial e eficácia como agente antimicrobiano e antiaderente do óleo essencial de Lavandula híbrida Grosso. Em especial sua atividade antiaderente desperta interesse por apresentar-se 4 vezes mais potente que o digluconato de clorexidina $0,12 \%$, podendo desse modo ser utilizado como método alternativo de inibição da formação do biofilme. No entanto, existe a necessidade de se realizar mais estudos sobre o assunto que venham esclarecer os mecanismos de ação e ajudar a combater a resistência microbiana.

\section{REFERÊNCIAS}

1. Dewhirst FE, Chen T, Izard J, Paster BJ, Tanner AC, Yu WH, Lakshmanan A, Wade WG. The human oral microbiome. J Bacteriol. 2010;192(19):5002-17.

2. Palmer RJ Jr. Composition and development of oral bacterial communities. Periodontol 2000. 2014;64(1):20-39.

3. Morais TMND, Silva AD, Avi ALRDO, Souza PHRD, Knobel E, Camargo LFA. A importância da atuação odontológica em pacientes internados em unidade de terapia intensiva. Rev bras ter intensiva. 2010;18(4):412-17.

4. Pina-vaz I, Barros J, Noites R, Villa-vigil A, Pintado M, Carvalho MF. Estratégias antimicrobianas na prevenção e tratamento da infecção oral. ICS UCP.. 2011;14(55):1-12.

5. Batista SA, Siqueira JSS, Silva Júnior A, Ferreira F, Agostini M, Torres SR. Alterações orais em pacientes internados em unidades de terapia intensiva. Rev Bras Odontol. 2014;71(2):156-59.

6. Gandolfo MC, Pessole T, Mendes G, Albara MF, Fontana A, Freisleben EV, et al. Uso dos colutórios em Odontologia. Ação Odonto. 2017;(2).

7. Muniz KGG. Atividade antimicrobiana in vitro de enxaguatórios bucais sobre bactérias do biofilme dentário. [Mmonografia]. Campina Grande: Centro de Ciências Biológicas e da Saúde - Universidade Estadual da Paraíba; 2014.

8. Oliveira MS, Borges $A H$, Mattos FZ, Semenoff TA, Segundo AS, Tonetto MR, Bandeca MC, Porto AN. Evaluation of different methods for removing oral biofilm in patients admitted to the intensive care unit. J Int Oral Health. 2014;6(3):61-4.

9. Alotaibi AK, Alshayiqi M, Ramalingam S. Does the presence of oral care guidelines affect oral care delivery by intensive care unit nurses? A 
survey of Saudi intensive care unit nurses. Am J Infect Control. 2014;42(8):921-22.

10. Cruz MK, Morais TMN, Trevisani DM. Clinical assessment of the oral cavity of patients hospitalized in an intensive care unit of an emergency hospital. Rev bras ter intensiva. 2012;26(4):379-83.

11. Oliveira LCBSD, Carneiro PPM, Fischer RG, Tinoco EMBA. presença de patógenos respiratórios no biofilme bucal de pacientes com pneumonia nosocomial. Rev bras ter intensiva. 2010;19(4):428-33.

12. ANVISA. Agência Nacional de Vigilância Sanitária. Ministério da Saúde. Pediatria: Prevenção e controle de infecção hospitalar/ Ministério da Saúde, Agência Nacional de Vigilância Sanitária. - Brasília: Ministério da Saúde, 2011.

13. Saigg NL, Silva MC. Efeitos da utilização do chá verde na saúde humana. Universitas: Ciências da Saúde. 2009;7(1):69-89.

14. Fernandes Júnior $A$, Silva GS, Barbosa LN, Alves FC, Andrade BF, Albano $M$ et al. Medicinal plants from the Brazilian savanna with antibacterial properties. European $\mathrm{J}$ Med Plants. 2012;4(1):1-13.

15. Baduy GA. Perspectivas para o emprego de plantas medicinais como recurso terapêutico em saúde bucal [monografia]. Rio de Janeiro: Fundação Oswaldo Cruz. Instituto de Tecnologia em Fármacos/Farmanguinhos; 2013.

16. Tardugno R, Serio A, Pellati F, D'Amato $S$, Chaves López C, Bellardi MG, Di Vito M, Savini V, Paparella A, Benvenuti S. Lavandula $x$ intermedia and Lavandula angustifolia essential oils: phytochemical composition and antimicrobial activity against foodborne pathogens. Nat Prod Res. 2019;33(22): 3330-335.

17. Cleeland L, Squires E. Evaluation of new antimicrobials in vitro and experimental animal infections. In: Lorian VMD. Antibiotics in Laboratory Medicine. Baltimore: Williams \& Wilkins; 1991.

18. Hadacek F, Greger H. Testing of antifungal natural products: methodologies, comparability of results and assay choice. Phytochem Anal. 2000;11:137-47.

19. Ncube NS, Afolayan AJ, Okoh Al. Assessment techniques of antimicrobial properties of natural compounds of plant origin: current methods and future trends. Afr j biotechnol. 2008;7(12): 1797-1806.

20. Guerra FQS, Mendes JM, De Oliveira WA, Da Costa JGM, Coutinho HDM, Lima EO. Chemical composition and antimicrobial activity of cinnamomum zeylanicum blume essential oil on multi-drug resistant Acinetobacter spp. strains. Biofar. 2012;8(1)62-70.
21. Gebara ECE, Zardetto CGDC, Mayer MPA. Estudo in vitro da açäo antimicrobiana de substâncias naturais sobre $S$. mutans e $S$. sobrinus. Rev Odontol Univ São Paulo. 1996;10(4):251-56.

22. Samuelsson G, Bohlin L. Drugs of natural origin: a treatise of pharmacognosy. CRC Press Inc; 2017.

23. Foglio MA, Queiroga CL, Sousa IDO, Rodrigues RAF. Plantas Medicinais como Fonte de Recursos Terapêuticos: Um Modelo Multidisciplinar. 2006. In: Construindo a História dos Produtos Naturais. MultiCiência. CPQBA/UNICAMP.

24. Sharma PK, Sangwan NS, Bose SK, Sangwan RS. Biochemical characteristics of a novel vegetative tissue geraniol acetyltransferase from a monoterpene oil grass (Palmarosa, Cymbopogon martinii var. Motia) leaf. Plant Sci. 2013;203-204:63-73.

25. Simões CM. O. Farmacognosia: da planta ao medicamento. UFRGS; Florianópolis: Universidade Federal de Santa Catarina; 2001.

26. Alizadeh A, Aghaee Z. Essential oil constituents, phenolic content and antioxidant activity of Lavandula stricta Delile growing wild in southern Iran. Nat Prod Res. 2016; 30(19):2253-7.

27. Prusinowska $R$, Śmigielski $K$, Stobiecka $A$, Kunicka-Styczyńska A. Hydrolates from lavender (Lavandula angustifolia)--their chemical composition as well as aromatic, antimicrobial and antioxidant properties. Nat Prod Res. 2016;30(4):386-93.

28. Sartoratto A, Machado A, Delarmelina C, Figueira G, Duarte M, Rehder L. Composition and antimicrobial activity of essential oils from aromatic plants used in Brazil. Braz $\mathrm{J}$ Microbiol. 2004;35:275-80.

29. Hafidh RR, Abdulamir AS, Vern LS, Abu Bakar $F$, Abas F, Jahanshiri F, Sekawi Z. Inhibition of growth of highly resistant bacterial and fungal pathogens by a natural product. Open Microbiol J. 2011;5:96-106.

30.Bajalan I, Rouzbahani R, Pirbalouti AG, Maggi F. Chemical Composition and Antibacterial Activity of Iranian Lavandula $\times$ hybrida. Chem Biodivers. 2017;14(7).

31. Andrade DP, Pallos D, Forte LFDBP, Ricardo LH. A doxiciclina como adjuvante no tratamento da periodontite. IJD. Int J Dent. 2009;8(4): 202-10.

32. Hortense SR, Silva-Carvalho E, Carvalho FS, Silva RPR, Magalhães Bastos JR,Silva Bastos $\mathrm{R}$. Uso da clorexidina como agente preventivo e terapêutico na odontologia. Rev Odontol Univ Cidade de São Paulo. 2017;22(2):178-84.

33. Vasconcelos T. Desenvolvimento de formulações contendo diferentes concentrações de digluconato de clorexidina e 
avaliação da estabilidade preliminar das formulações. Acta Farm Portuguesa. 2015;4(2):134-40.

34. Bohner LOM. Ação do enxaguatório bucal a base de Casearia Sylvestris e Clorexidina 0, $12 \%$ na cor e rugosidade superficial do esmalte dental submetido ao clareamento caseiro e bebida alimentícia ácida [tese]. São Paulo: Universidade de São Paulo; 2013.

35. Castro SL. "In vivo" Study efficacy of anti septics on microaerobic microorganisms of the oral cavity. Rev Dent. 2001;1:1-9.

36. Rajasekharan SK, Ramesh S, Satish AS, Lee J. Antibiofilm and Anti- $\beta$-Lactamase Activities of Burdock Root Extract and Chlorogenic Acid against Klebsiella pneumoniae. J Microbiol Biotechnol. 2017;27(3):542-51.

\section{CONFLITO DE INTERESSES}

Os autores declaram não haver conflitos de interesse

\section{AUTOR PARA CORRESPONDÊNCIA}

José Henrique de Araújo Cruz

Rua Paulo Diogenes, 57 - Centro 59990-000 Rafael Fernandes - RN, Brasil

Telefone: (83) 99625-0125.

E-mail: henrique_araujo1992@hotmail.com 